\title{
New-Onset Atrial Fibrillation in St-Segment Elevation Myocardial Infarction: Predictors and Impact on Therapy And Mortality
}

\author{
Kisa Hyde Congo, ${ }^{1}$ Adriana Belo, ${ }^{2}$ João Carvalho, ${ }^{1}$ David Neves, ${ }^{1}$ Rui Guerreiro, ${ }^{1}$ João António Pais, ${ }^{1}$ Diogo Brás, ${ }^{1}$ \\ Mafalda Carrington, ${ }^{1}$ Bruno Piçarra, ${ }^{1}$ Ana Rita Santos, ${ }^{1}$ José Aguiar ${ }^{1}$ \\ Hospital Espírito Santo de Évora, ${ }^{1}$ Évora - Portugal \\ Centro Nacional Coleção de Dados em Cardiologia, ${ }^{2}$ Coimbra - Portugal
}

\section{Abstract}

Backgrund: New-onset atrial fibrillation complicating acute myocardial infarction represents an important challenge, with prognostic significance.

Objective: To study the incidence, impact on therapy and mortality, and to identify predictors of development of new-onset atrial fibrillation during hospital stay for ST-segment elevation myocardial infarction.

Methods: We studied all patients with ST-elevation myocardial infarction included consecutively, between 2010 and 2017 , in a Portuguese national registry and compared two groups: 1 - no atrial fibrillation and 2 - new-onset atrial fibrillation. We adjusted a logistic regression model data analysis to assess the impact of new-onset atrial fibrillation on in-hospital mortality and to identify independent predictors of its development. A p value $<0.05$ was considered significant.

Results: We studied 6325 patients, and new-onset atrial fibrillation was found in 365 (5.8\%). Reperfusion was successfully accomplished in both groups with no difference regarding type of reperfusion. In group 2, therapy with beta-blockers and angiotensin-conversion enzyme (ACE) inhibitors/angiotensin receptor blockers (ARBs) was less frequent, $20.6 \%$ received anticoagulation at discharge and $16.1 \%$ were on triple therapy. New-onset atrial fibrillation was associated with more in-hospital complications and mortality. However, it was not found as an independent predictor of in-hospital mortality. We identified age, prior stroke, inferior myocardial infarction and complete atrioventricular block as independent predictors of new-onset atrial fibrillation.

Conclusion: New-onset atrial fibrillation remains a frequent complication of myocardial infarction and is associated with higher rate of complications and in-hospital mortality. Age, prior stroke, inferior myocardial infarction and complete atrioventricular block were independent predictors of new onset atrial fibrillation. Only $36.7 \%$ of the patients received anticoagulation at discharge. (Arq Bras Cardiol. 2019; 113(5):948-957)

Keywords: Atrial Fibrillation; ST Elevation Myocardial Infarction/complications; Hospitalization; Mortality; Antihypertensive; Anticoagulants.

\section{Introduction}

Atrial fibrillation (AF) is the most commonly encountered arrhythmia and often complicates acute myocardial infarction (AMI) with new-onset atrial fibrillation of $6-21 \% .{ }^{1}$ In this clinical setting, the occurrence of AF is significant, since rapid and irregular ventricular rates can further impair coronary circulation. The etiology of AF in this context, as in critical illnesses, is most likely multifactorial and includes ischemia, reduced atrial perfusion, glycolytic anaerobic pathways, inflammation, neurohumoral factors, autonomic regulation abnormalities, high left ventricular end-diastolic pressure and elevated atrial pressure. $^{2-4}$ The bulk of evidence demonstrates that AF in patients hospitalized for AMI represents an important challenge,

Mailing Address: Kisa Hyde Congo

Hospital Espírito Santo de Évora - Largo Senhor da Pobreza, s/n Évora 7000-811 - Portugal

E-mail: kisacongo@gmail.com, kisahydecongo@gmail.com

Manuscript received October 05, 2018, revised manuscript January 04, 2019, accepted February 13, 2019

DOI: $10.5935 / a b c .20190190$ concerning the role of antiarrhythmic drugs and antithrombotic treatment. ${ }^{1,2}$ The development of AF is linked to poorer prognosis and adverse impact on in-hospital and long-term mortality. ${ }^{5,6}$ This seems to also apply for transient AF, which has reversed back to sinus rhythm at the time of discharge.

With advancements in reperfusion strategies and contemporary treatment with angiotensin-conversion enzyme (ACE) inhibitors, statins and antiplatelet therapy, it could be anticipated that there would be a change in incidence and prognostic impact of $\mathrm{AF}$ in the setting of $\mathrm{AMI} .^{2}$

The purpose of this study was to determine the incidence of AF in patients hospitalized for ST-segment elevation myocardial infarction (STEMI), identify predictors of AF development and analyze its impact on therapy and in-hospital mortality, in the setting of AMI managed according to the most recent guideline strategies.

\section{Methods}

We performed a multicenter retrospective cohort study and identified all hospital admissions from October 2010 to August 2017 with primary discharge diagnosis of ST-segment elevation 
myocardial infarction included consecutively in a national multicenter Portuguese registry on Acute Coronary Syndromes (ProACS). This Portuguese registry includes 25 cardiology departments and has received the approval and authorization from the National Committee of Data Protection (authorization number 3140/2010) and is registered at ClinicalTrials.gov with identification number NCT 01642329

We used the third universal definition of STEMI as a new ST-segment elevation at the J point $\geq 0.1 \mathrm{mV}$ in two contiguous leads or new left bundle branch block, for over 30 minutes, in a clinical setting consistent with acute myocardial ischemia.

New-onset AF was defined as first occurrence of AF at the time of the myocardial infarction (MI) or any time after $\mathrm{MI}$ onset, in the absence of prior diagnosis.

We divided the patients into 2 groups: Group 1 - Patients who did not develop AF during in-hospital stay for STEMI and Group 2 - Patients with new-onset AF during in-hospital stay for STEMI. We excluded patients with previous diagnosis of AF or previous anticoagulation therapy.

In each patient, baseline clinical characteristics, including demographics and patient history (cardiovascular and noncardiovascular comorbidities) were collected. Data relating to coronary angiography, percutaneous coronary intervention (namely, number of affected vessels and number of treated vessels) left ventricular function (assessed either by echocardiography, magnetic resonance, computed tomography, angiography or radionuclide imaging) and in-hospital and post-discharge medical therapy was also analyzed. The outcome variables studied were in-hospital mortality and complications, namely: heart failure, cardiogenic shock, stroke, major bleeding, atrioventricular (AV) block, ventricular tachycardia, cardiac arrest, mechanical complications of AMI and need for invasive mechanical ventilation, Swan-Ganz catheter, transvenous cardiac pacing, intra-aortic balloon pump or ventricular assist device.

We compared the defined outcomes in both groups and performed multivariate data analysis to assess independent predictors for new-onset AF and the impact of new-onset AF on in-hospital mortality.

The study protocol is in accordance with the Declaration of Helsinki.

\section{Data analysis}

Categorical variables were characterized by absolute and relative frequencies, and numerical variables by means and standard deviations for symmetric distributions; for asymmetric distributions, medians and interquartile intervals were used. Normality was assessed by the Kolmogorov-Smirnov test.

Comparisons between both groups regarding categorical variables were conducted using the chi-square Test or Fisher's exact Test. For the continuous variables, unpaired t-tests were used to compare the means whenever possible, otherwise, the Mann-Whitney $U$ test was used to compare the medians.

Predictors were determined by adjusting the logistic regression model. Variables were selected to be included in the model using the stepwise (forward) method, together with the likelihood-ratio test. For each variable included in the regression model, adjusted odds ratio and 95\% confidence interval (C195\%) were also estimated. The quality of the adjustment of the models was assessed by determining the area under the Receiver Operating Characteristic curve (AUC) and its sensitivity and specificity.

A Kaplan-Meier estimate was obtained for time to death. Comparison of two survival functions was conducted by log-rank test.

Statistical analyses were conducted using SPSS $19.0^{\circledR}$ at a $5 \%$ significance level for hypothesis-testing.

\section{Results}

A total of 6957 patients with primary diagnosis of ST-segment elevation myocardial infarction were identified. We excluded 632 patients due to previous diagnosis of $A F$, previous anticoagulation therapy or missing information. A total of 6325 patients were enrolled (Figure 1). New-onset AF was found in 365 patients (5.8\%). Overall baseline characteristics and of both groups are summarized in Table 1.

Regarding patient demographics and comorbidities, patients who developed new-onset AF were older, with higher prevalence of female sex, higher prevalence of hypertension, diabetes mellitus, prior coronary artery bypass grafting (CABG), valvular heart disease, prior heart failure (HF), prior stroke, peripheral arterial disease, chronic obstructive pulmonary disease (COPD) and dementia. There was lower prevalence of smoking habits and family history of coronary disease in group 2. No difference between both groups was found regarding the other characteristics analyzed.

Clinical data at admission is shown in Table 2. Patients in group 2 had higher heart rates and lower systolic blood pressure at admission. Patients in group 2 presented heart failure more frequently.

Regarding therapy, reperfusion was successfully accomplished in both groups (Figure 2), with no significant difference. However, patients who developed AF had a longer time from symptom onset to reperfusion [median 243 (166-400) minutes vs. 267 (185-398) minutes, $p=0.033$ ] The number of patients who underwent coronary angiography or angioplasty was not statistically different. No difference in the number of affected vessels was found, although patients in group 2 had a higher prevalence of left main coronary artery disease (3.0\% vs. $5.2 \%, p=0.041)$, with no difference regarding other vessel disease. Patients in group 2 had implanted more bare-metal stents $(25.1 \%$ vs. $35.4 \%$, $\mathrm{p}=0.003)$. Thrombectomy devices were more frequently used in patients in group $2(32.5 \%$ vs. $42.9 \%, \mathrm{p}<0.001)$.

Medical therapy during in-hospital stay and at discharge are shown in Tables 3, 4 and 5. Most patients developed new-onset AF on the first day [median 0 (0-1) days; mean $1.2 \pm 3.5$ days]

New-onset AF was associated with higher rate of in-hospital complications, namely: worse left ventricular function, higher prevalence of HF, cardiogenic shock, AV block, ventricular tachycardia, cardiac arrest, mechanical complications, stroke and major bleeding (Table 6). 


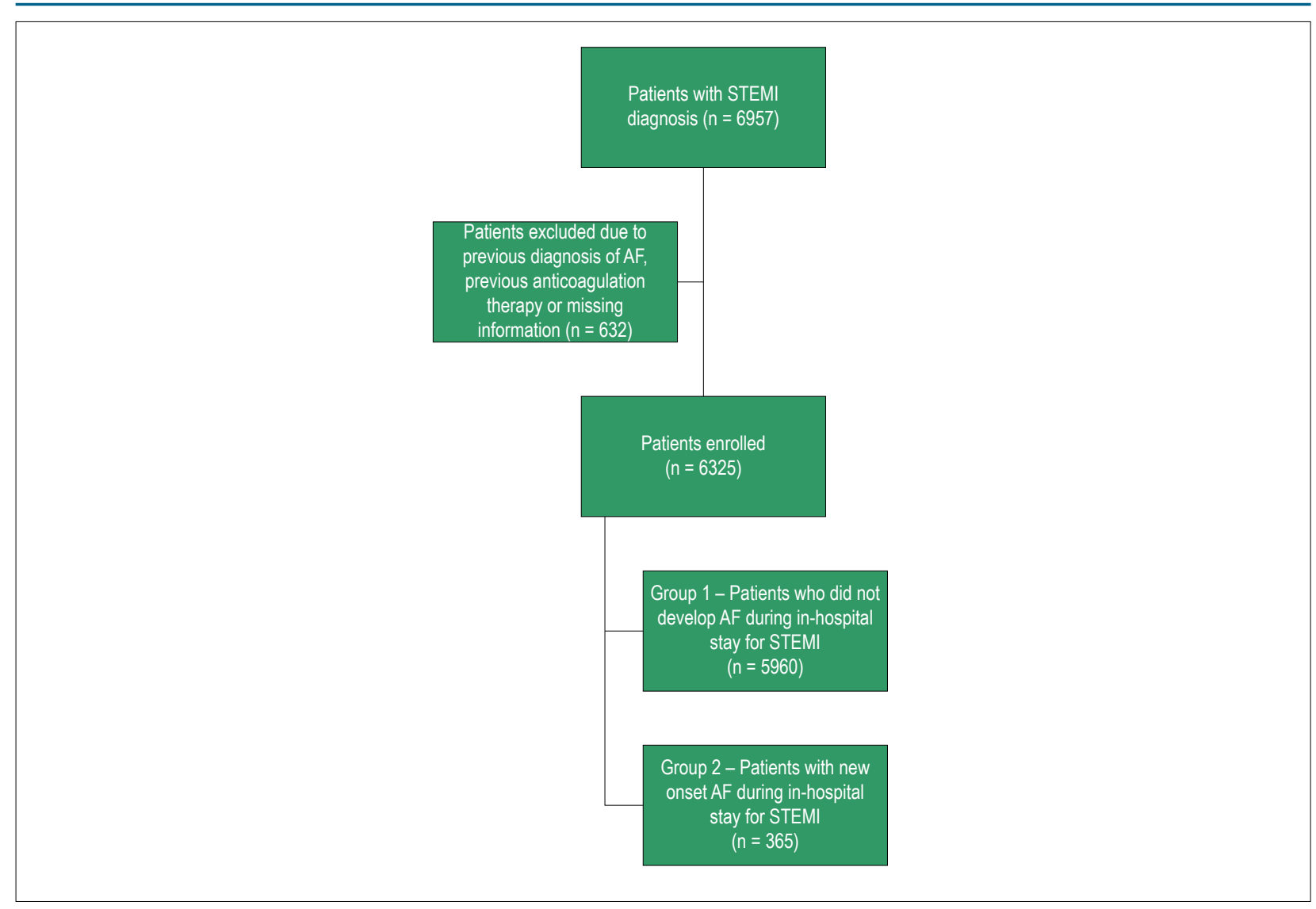

Figure 1 - Flowchart with patients included and excluded.

It was also associated to a more frequent need of Swan-Ganz catheter, intra-aortic balloon pump, invasive mechanical ventilation and transvenous cardiac pacing (Table 7). The duration of hospital stay was higher in patients of group 2 [3 $(3 ; 5)$ days vs. $5(4 ; 9)$ days, p < 0.001]. In-hospital mortality was higher in patients who developed new onset AF (3.8\% vs. $13.4 \% ; p<0.001)$ (Figure 3 ). Although new-onset AF was associated with higher incidence of complications and in-hospital mortality, by multivariate analysis, new-onset AF was not found as an independent predictor of in-hospital mortality [OR 1.19 (0.62-2.27), $\mathrm{p}=0.608]$.

We identified age, prior stroke, inferior located STEMI and complete AV block as independent predictors of new-onset AF (Table 8).

\section{Discussion}

These population-based data reflect the comprehensive experience of a community in a "real-life" setting and is more representative of those treated in clinical practice than populations enrolled in randomized controlled trials.

In our population, new-onset AF was found in 5.8\% of patients hospitalized for STEMI, which is in line with recent published data. ${ }^{1,7}$ However, this number is lower than most older studies, suggesting that despite an increasingly older population with higher prevalence of comorbidities, the incidence of $\mathrm{AF}$ in the setting of acute $\mathrm{MI}$ has declined. ${ }^{8,9}$

New-onset AF was found more frequently in older patients, female sex, with higher prevalence of comorbidities, including hypertension, diabetes, previous stroke and previous heart failure and, therefore, higher $\mathrm{CHA}_{2} \mathrm{DS}_{2}-\mathrm{VASC}$ scores. According to Schmitt et al., ${ }^{1}$ the use of interventional coronary revascularization has been associated with a notable decline in the AF incidence. ${ }^{1}$ However, one of the major findings of this study is that new-onset AF complicating STEMI is independent of reperfusion strategy. Reperfusion was successfully accomplished in both groups with no difference regarding the type of reperfusion and no difference in the number of affected or treated vessels between both groups. This is consistent with the OACIS study, which states that AF complicating the clinical course of MI appears to be irrespective of treatment by thrombolytics or $\mathrm{PCl} .{ }^{10,11}$ However, there seems to be a favorable effect of early reperfusion therapy on preventing new-onset $A F$, as it also was suggested by a previous study. ${ }^{8}$ The use of thrombectomy devices, which may suggest a cardioembolic cause, were more frequently used in patients who developed $A F$, raising the question that some patients with new-onset AF may have had undiagnosed paroxysmal AF. ${ }^{12}$ 
Original Article

Table 1 - Baseline characteristics

\begin{tabular}{|c|c|c|c|c|c|}
\hline \multirow{2}{*}{$\mathbf{N}$} & All & Group 1 - No AF & Group 2 - New onset AF & \multirow{2}{*}{$\mathrm{p}$} & \multirow{2}{*}{$\mathrm{OR}(\mathrm{Cl} 95 \%)$} \\
\hline & 6325 & $5960(94.2 \%)$ & $365(5.8 \%)$ & & \\
\hline Female (\%) & 24.2 & 23.6 & 34.2 & $<0.001$ & $1.69(1.35-2.12)$ \\
\hline \multirow{2}{*}{ Age (years) $\geq 75(\%)$} & $63 \pm 13$ & $62 \pm 13$ & $71 \pm 13$ & $<0.001$ & \multirow{2}{*}{$3.24(2.61-4.01)$} \\
\hline & 21.6 & 20.1 & 44.9 & $<0.001$ & \\
\hline $\mathrm{BMI}>30(\%)$ & 20.1 & 20.2 & 18.3 & 0.413 & $0.89(0.67-1.18)$ \\
\hline Arterial hypertension (\%) & 59.6 & 59.0 & 69.1 & $<0.001$ & $1.55(1.23-1.95)$ \\
\hline Diabetes mellitus (\%) & 23.7 & 23.4 & 28.8 & 0.021 & $1.32(1.04-1.67)$ \\
\hline Dyslipidemia (\%) & 51.1 & 51.4 & 47.7 & 0.186 & $0.86(0.69-1.07)$ \\
\hline Smoking habits (\%) & 38.6 & 39.3 & 28.6 & $<0.001$ & $0.55(0.43-0.69)$ \\
\hline Family history of coronary disease (\%) & 8.5 & 8.8 & 2.4 & $<0.001$ & $0.25(0.12-0.53)$ \\
\hline Prior MI (\%) & 10.1 & 10.1 & 9.9 & 0.881 & $0.97(0.68-1.39)$ \\
\hline Prior PCl (\%) & 8.5 & 8.7 & 5.8 & 0.051 & $0.64(0.41-1.00)$ \\
\hline Prior CABG (\%) & 1.0 & 0.9 & 2.5 & 0.011 & $2.71(1.33-5.52)$ \\
\hline Valvular heart disease $(\%)$ & 0.9 & 0.7 & 3.4 & $<0.001$ & $4.61(2.41-8.81)$ \\
\hline History of heart failure (\%) & 1.4 & 1.3 & 3.6 & $<0.001$ & $2.81(1.55-5.11)$ \\
\hline Previous stroke (\%) & 5.4 & 5.0 & 10.4 & $<0.001$ & $2.19(1.53-3.12)$ \\
\hline Peripheral artery disease (\%) & 2.6 & 2.5 & 5.0 & 0.004 & $2.06(1.25-3.40)$ \\
\hline Pacemaker/ ICD (\%) & 0.4 & 0.4 & 0.5 & 0.647 & $1.48(0.35-6.32)$ \\
\hline Chronic renal disease (\%) & 2.9 & 2.8 & 4.1 & 0.132 & $1.51(0.88-2.59)$ \\
\hline CPOD (\%) & 3.4 & 3.2 & 6.9 & $<0.001$ & $2.23(1.45-3.43)$ \\
\hline Dementia (\%) & 1.9 & 1.7 & 5.3 & $<0.001$ & $3.18(1.92-5.27)$ \\
\hline
\end{tabular}

Table 2 - Clinical data at admission

\begin{tabular}{|c|c|c|c|c|}
\hline & All & No AF & New onset AF & $\mathrm{p}$ \\
\hline \multicolumn{5}{|l|}{ AMI (\%) } \\
\hline - Anterior & 48.4 & 48.4 & 49.0 & 0.806 \\
\hline - Inferior & 50.6 & 50.6 & 49.6 & 0.704 \\
\hline- LBBB & 1.0 & 1.0 & 1.4 & 0.424 \\
\hline \multirow{2}{*}{ Heart rate $(\mathrm{bpm})>100 \mathrm{bpm}(\%)$} & $77 \pm 19$ & $77 \pm 18$ & $79 \pm 24$ & 0.066 \\
\hline & 11.7 & 11.3 & 18.7 & $<0.001$ \\
\hline \multirow{2}{*}{ Systolic arterial pressure $(\mathrm{mmHg})<100 \mathrm{mmHg}(\%)$} & $135 \pm 30$ & $135 \pm 30$ & $126 \pm 28$ & $<0.001$ \\
\hline & 12.3 & 12.0 & 18.1 & 0.001 \\
\hline \multirow{2}{*}{ Diastolic arterial pressure $(\mathrm{mmHg})<60 \mathrm{mmHg}(\%)$} & $80 \pm 18$ & $80 \pm 18$ & $76 \pm 17$ & $<0.001$ \\
\hline & 14.6 & 14.4 & 17.5 & 0.102 \\
\hline Killip-Kimbal class $\geq 2(\%)$ & 13.0 & 12.1 & 27.3 & $<0.001$ \\
\hline \multirow{2}{*}{ Creatinine $(\mathrm{mg} / \mathrm{dL}) \geq 2 \mathrm{mg} / \mathrm{dL}(\%)$} & $1 \pm 0.8$ & $1 \pm 0.8$ & $1.2 \pm 0.9$ & $<0.001$ \\
\hline & 3.6 & 3.3 & 8.5 & $<0.001$ \\
\hline \multirow{2}{*}{ Hemoglobin (g/dL) $\geq 12$ g/dL (\%) } & $14.1 \pm 1.8$ & $14.1 \pm 1.8$ & $13.5 \pm 2$ & $<0.001$ \\
\hline & 87.8 & 88.2 & 81.3 & $<0.001$ \\
\hline
\end{tabular}

Values are mean $\pm S D$, median (P25; P75) or $n(\%)$. AF: atrial fibrillation; AMI: acute myocardial infarction; LBBB: left bundle branch block. 


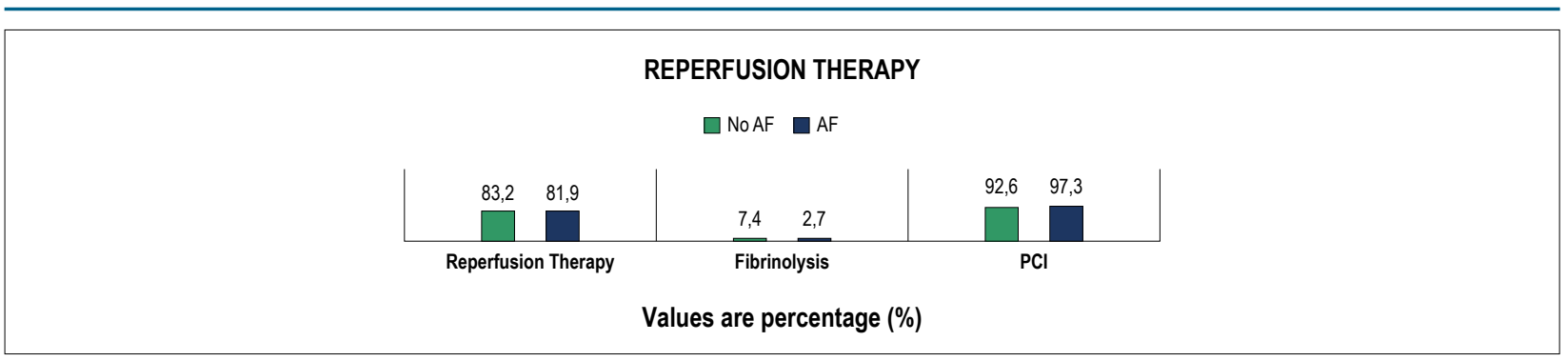

Figure 2 - Reperfusion therapy. AF: atrial fibrillation; PCl: percutaneous coronary intervention.

Table 3 - Medical therapy during in-hospital stay Values are percentage (\%)

\begin{tabular}{|c|c|c|c|c|}
\hline & All & Group 1 - No AF & Group 2 - New onset AF & $p$ \\
\hline Aspirin & 98.6 & 98.6 & 99.2 & 0.349 \\
\hline Clopidogrel & 86.7 & 86.6 & 89.3 & 0.138 \\
\hline Ticagrelor & 17.6 & 17.9 & 12.3 & 0.042 \\
\hline Prasugrel & 0 & 0 & 0 & \\
\hline Other AP & 5.4 & 5.5 & 5.2 & 0.859 \\
\hline GPIlbllla inhibitors & 33.6 & 33.5 & 35.8 & 0.362 \\
\hline UFH & 46.3 & 46.3 & 45.6 & 0.784 \\
\hline Fondaparinux & 6.1 & 6.0 & 7.7 & 0.185 \\
\hline Bivalirudin & 0.7 & 0.6 & 0.8 & 0.512 \\
\hline LMWH & 45.1 & 44.3 & 58.2 & $<0.001$ \\
\hline Vitamin $\mathrm{K}$ antagonists & 1.3 & 1.0 & 5.2 & $<0.001$ \\
\hline NOAC & 0.3 & 0.3 & 0.8 & 0.106 \\
\hline Beta-blockers & 79.6 & 80.2 & 69.5 & $<0.001$ \\
\hline ACE inhibitors/ARB & 86.3 & 86.6 & 80.8 & 0.002 \\
\hline Aldosterone antagonists & 13.5 & 12.6 & 27.3 & $<0.001$ \\
\hline Statins & 94.6 & 94.5 & 95.6 & 0.364 \\
\hline Diuretics & 25.1 & 23.0 & 58.5 & $<0.001$ \\
\hline Amiodarone & 6.5 & 2.9 & 65.9 & $<0.001$ \\
\hline Other antiarrhythmic drugs & 1.0 & 0.9 & 1.9 & 0.08 \\
\hline Digitalis & 0.9 & 0.3 & 11.3 & $<0.001$ \\
\hline Inotropes & 7.8 & 6.6 & 27.3 & $<0.001$ \\
\hline Levosimendan & 1.0 & 0.7 & 5.5 & $<0.001$ \\
\hline
\end{tabular}

AF: atrial fibrillation; AP: antiplatelet therapy; Gpllb/IIIA inhibitors: Glycoprotein Ilb/Ila inhibitors; LMWH: low molecular weight heparin; UFH: unfractionated heparin.

There is insufficient data indicating preferences for rate or rhythm control in AF complicating STEMI. Besides beta-blockers, antiarrhythmic drug use is usually limited to amiodarone..$^{13}$ In our population, two-thirds of the patients who developed new onset AF were started on amiodarone.

Selection of antithrombotic therapy was at the discretion of the attending physician and reflects a wide range of therapeutic strategies in a "real-life" setting. Considering the most recent guidelines published by the European Society of Cardiology, the recommendation is that STEMI patients with an indication for oral anticoagulation, as in $\mathrm{AF}$, should be considered for triple therapy with aspirin, clopidogrel and oral anticoagulant for 1-6 months. ${ }^{13,14}$ As shown in Table 5, in this population, only $16.1 \%$ were on triple therapy at discharge, $10.2 \%$ with AAS, clopidogrel and vitamin $\mathrm{K}$ antagonists, and $5.9 \%$ on AAS, clopidogrel and non-vitamin $\mathrm{K}$ anticoagulant (NOAC). This low rate of triple therapy in STEMI patients with AF has been reported in other studies, such as the APEX-AMI study, where $10.6 \%$ of new-onset AF patients hospitalized for STEMI were on triple therapy. ${ }^{15}$ Seventeen percent of patients in group 2 were on $\mathrm{P}_{2} \mathrm{Y}_{12}$ inhibitors other than clopidogrel and none of these were on anticoagulants at discharge. It is noteworthy that $6.1 \%$ of patients on aspirin during in-hospital stay were not on aspirin when discharged, suggesting that a WOEST 
Original Article

Table 4 - Medical therapy at discharge

\begin{tabular}{lcccc}
\hline & All & Group 1 - No AF & Group 2 - New onset AF & p \\
\hline Aspirin & 96.2 & 96.3 & 93.1 & 0.005 \\
Clopidogrel & 80.3 & 80.2 & 81.3 & 0.634 \\
Ticagrelor & 19.3 & 19.6 & 13.7 & 0.065 \\
Prasugrel & 0.3 & 0.3 & 0 & 1.000 \\
Other AP & 4.9 & 5.0 & 3.6 & 0.289 \\
Vitamin K antagonists & 2.4 & 1.9 & 11.2 & $<0.001$ \\
NOACs & 1.2 & 7.9 & $<0.001$ \\
Beta-blockers & 81.6 & 71.1 & $<0.001$ \\
ACE inhibitors/ARB & 87.7 & 81.3 & $<0.001$ \\
Aldosterone antagonists & 12.0 & 82.2 & 26.0 & $<0.001$ \\
Diuretics & 20.1 & 88.0 & 46.6 & $<0.001$ \\
Amiodarone & 2.4 & 11.2 & 26.4 & $<0.001$ \\
Other antiarrhythmic drugs & 0.1 & 18.7 & 0 & 1.000 \\
Digitalis & 0.4 & 1.1 & 4.0 & $<0.001$ \\
\hline
\end{tabular}

Values are percentage (\%). AF: atrial fibrillation; NOAC: non vitamin K anticoagulant.

Table 5 - Patients from group 2 on triple therapy

\begin{tabular}{lc}
\hline Antithrombotic therapy & Group 2 - New onset AF \\
\hline Aspirin + Clopidogrel + Vitamin K antagonists & 10.2 \\
Aspirin + Clopidogrel + NOACs & 5.9 \\
Aspirin + Ticagrelor/Prasugrel + Vitamin K antagonists & 0 \\
Aspirin + Ticagrelor/Prasugrel + NOACs & 0 \\
Total & 16.1 \\
\hline
\end{tabular}

Values are percentage (\%). AF: atrial fibrillation; ACE inhibitors: angiotensin conversion enzyme inhibitors; ARB: angiotensin receptor blockers; NOAC: non vitamin $K$ anticoagulant.

Table 6 - In-hospital complications

\begin{tabular}{lcccc}
\hline & All & Group 1 - No AF & Group 2 - New onset AF & p \\
\hline LV Ejection fraction $<50 \%$ & 43.4 & 42.2 & 62.1 & $p<0.001$ \\
Heart failure & 16.8 & 14.9 & 48.5 & $p<0.001$ \\
Cardiogenic shock & 5.9 & 4.9 & 22.3 & $p<0.001$ \\
Atrioventricular block & 5.3 & 4.8 & 14.2 & $p<0.001$ \\
Ventricular tachycardia & 2.6 & 2.1 & 10.7 & $p<0.001$ \\
Cardiac arrest & 5.2 & 4.8 & 11.8 & $p<0.001$ \\
Mechanical complications & 1.3 & 1.2 & 3.3 & $p=0.002$ \\
Stroke & 0.7 & 0.6 & 2.5 & $p=0.001$ \\
Major bleeding & 1.9 & 1.6 & 6.8 & $p<0.001$ \\
\hline
\end{tabular}

Values are percentage (\%). AF: atrial fibrillation; LV: left ventricular 


\section{Original Article}

Table 7 - Invasive procedures performed

\begin{tabular}{lcc}
\hline & OR (CI 95\%) & $p$ \\
\hline Age & $1.02(1.01-1.04)$ & $p<0.001$ \\
Prior stroke & $1.87(1.09-3.21)$ & $p=0.023$ \\
Inferior located STEMI & $1.57(1.13-2.18)$ & $p=0.007$ \\
Complete AV block & $1.94(1.19-3.16)$ & $p=0.008$ \\
\hline
\end{tabular}

Values are percentage (\%). AF: atrial fibrillation

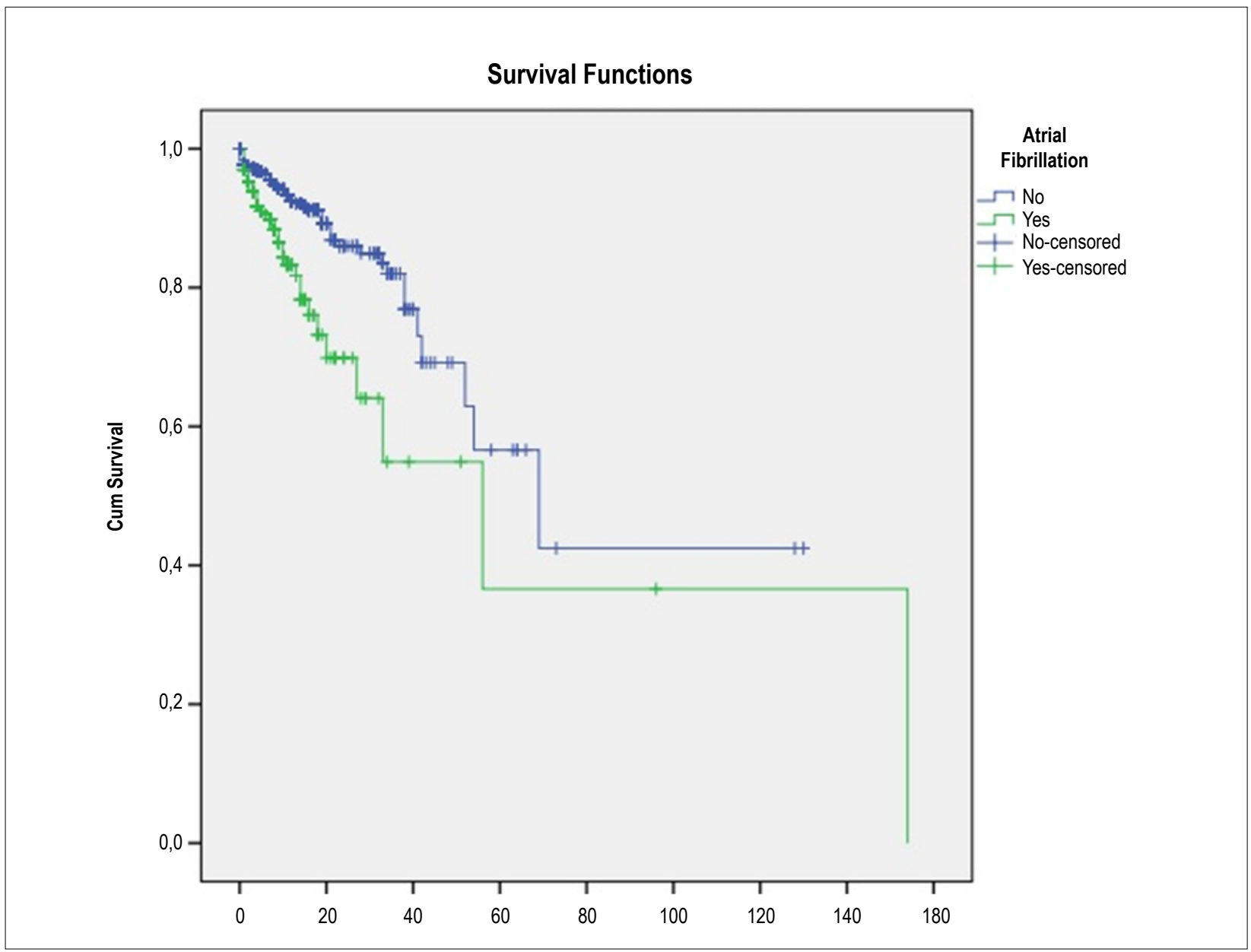

Figure 3 - Kaplan-Meier survival curves for the two groups.

trial-like strategy was chosen, which is also supported by a meta-analysis that suggests that a combination of vitamin $\mathrm{K}$ antagonists and single antiplatelet therapy is the best choice for $\mathrm{AF}$ patients undergoing percutaneous coronary intervention (PCI) considering both efficacy and safety. ${ }^{16,17}$ Stenestrand et al. ${ }^{18}$ and Lopes et al. ${ }^{15}$ showed that only a small percentage of patients with $\mathrm{AF}$ and acute $\mathrm{MI}$ received oral anticoagulation therapy at discharge (30\% and $43.4 \%$, respectively). Our results show a lower rate of anticoagulation: only $20.6 \%$ of patients diagnosed with AF during in-hospital stay received oral anticoagulation at discharge. Forty-five percent of patients on anticoagulation at discharge were on NOACs.

Therapy with beta-blockers and angiotensin-conversion enzyme (ACE) inhibitors/angiotensin receptor blockers (ARBs) was less frequently found in patients who developed new-onset AF and although the higher incidence of complications may have limited therapeutic options, this could suggest that renin-angiotensin-aldosterone system inhibitors and 
Table 8 - Independent predictors of new onset atrial fibrillation

\begin{tabular}{|c|c|c|c|c|}
\hline & All & Group 1 - No AF & Group 2 - New onset AF & p \\
\hline Swan-Ganz catheter & 0.6 & 0.4 & 3.6 & $p<0.001$ \\
\hline Intra-aortic balloon pump & 1.2 & 1.1 & 2.7 & $p=0.012$ \\
\hline Invasive mechanical ventilation & 3.5 & 3.2 & 9.0 & $p<0.001$ \\
\hline Transvenous cardiac pacing & 3.6 & 3.1 & 11.2 & $p<0.001$ \\
\hline
\end{tabular}

STEMI: ST-segment elevation myocardial infarction

beta-blockers may have a protective role, which is in line with previous studies. ${ }^{1,19,20}$ No difference was found regarding statin therapy, unlike what was suggested in previous studies. ${ }^{21}$

New-onset AF was associated with higher incidence of complications, namely stroke, heart failure, cardiogenic shock, arrhythmias, cardiac arrest, mechanical complications and major bleeding, and in-hospital mortality, but was not found as an independent predictor of mortality, suggesting that new-onset AF complicating STEMI may simply be an indicator of poor overall clinical status, which is consistent with previous studies. ${ }^{5,22}$ Studies on critically ill patients also suggest new-onset AF is an indicator of clinical severity and poorer prognosis. ${ }^{4,23-25}$

Age, prior stroke, inferior STEMI and complete AV block were found as independent predictors of new-onset AF.

Age and prior stroke reflect patients with more comorbidities. A systematic review by Schmitt et al. ${ }^{1}$ of 20 publications also found that new-onset AF is more likely to complicate AMI in older patients. ${ }^{1}$ Anatomic atrial abnormalities with aging, such as atrial fibrosis and smooth muscle cell proliferation, may provide anatomic substrate for the multiple wavelet re-entry mechanism of AF. ${ }^{26}$

Logistic regression analysis showed that inferior STEMI was an independent predictor of new-onset AF in our population. Kyriakidis et al. ${ }^{27}$ found that all patients that developed supraventricular arrhythmia had inferior STEMI and right and left atrial ischemia, and concluded that ischemia of the sinus node due to coronary occlusion proximal to the origin of the sinus node artery was probably one of the underlying causes of atrial fibrillation. ${ }^{27}$ According to Tjandrawidjaja et al., ${ }^{28}$ the compromised anatomy of the principal coronary atrial branches is associated with the development of atrial arrhythmia. ${ }^{28}$

The GUSTO III study found that the development of AF could be due to other post-AMI complications occurring before $A F$, such as complete AV block. ${ }^{26}$ An association between complete AV block and incidence of AF has also been reported previously, particularly in AH type of AV block, due to lesions observed in the atrial muscles including the internodal tracts. ${ }^{29}$

The main question of long-term management of new-onset AF in STEMI and whether to start anticoagulation therapy in these patients remains unanswered, as there is not enough data. In our population, only one in five patients was discharged on oral anticoagulation. Follow-up data on these patients is needed to assess long-term complications. According to some studies, new-onset AF in the acute setting may indicate a propensity to develop arrhythmia again, potentially because of associated comorbidities or other predisposing factors. ${ }^{3}$ In our population, the therapeutic strategy seems to have been based on the notion that new-onset AF in STEMI could represent a transient complication of acute coronary syndrome, as suggested by some studies that have shown that in patients with coronary artery disease, atrial ischemia independently promotes the formation of a substrate for $\mathrm{AF}$ and that atrial impulse conduction abnormalities were abolished after reperfusion was achieved with either thrombolysis or primary percutaneous coronary intervention $(\mathrm{PCl}) .{ }^{8,30,31}$

\section{Study limitations}

Although data have been prospectively acquired, the main limitations of this study derive from its retrospective design, which limits some available data.

Another limitation is that some patients diagnosed with new-onset AF may in fact have previous yet undiagnosed paroxysmal $\mathrm{AF}$, which may lead to an overestimated incidence. These patients may also represent a different subtype of patients, compared to actual new-onset AF due to the ischemic event.

\section{Conclusions}

This study reflects a very large registry of new-onset AF in patients hospitalized for STEMI. It shows that in a modern revascularization era, $\mathrm{AF}$ is still a frequent complication of acute myocardial infarction. It can be reduced by early reperfusion independently of reperfusion strategy. These registry data confirm the high mortality and morbidity associated with $\mathrm{AF}$, which may suggest the importance of identifying this subgroup of STEMI patients. Age, prior stroke, inferior STEMI and complete AV block were found as independent predictors of new-onset AF in the setting of STEMI. Furthermore, data indicates that only a minority of patients receive oral anticoagulants at discharge. Although the incidence has decreased, we can still expect AF to remain a frequent and worrisome complication of AMI. Further studies answering questions such as how to reduce the risk of AF development, whether the use of new generation drug-eluting stents and modern antithrombotic strategies aimed at better reperfusion wil reduce the incidence of new-onset AF during AMI and how to determine the optimal use of oral anticoagulation therapy in combination with antiplatelet therapy in this setting. 


\section{Author contributions}

Conception and design of the research, Analysis and interpretation of the data and Writing of the manuscript: Congo $\mathrm{KH}$; Statistical analysis: Belo A; Critical revision of the manuscript for intellectual content: Belo A, Carvalho J, Neves D, Guerreiro R, Pais JA, Brás D, Carrington M, Piçarra B, Santos AR, Aguiar J.

\section{Potential Conflict of Interest}

No potential conflict of interest relevant to this article was reported.

\section{Sources of Funding}

There were no external funding sources for this study.

\section{Study Association}

This study is not associated with any thesis or dissertation work.

\section{Ethics approval and consent to participate}

This study was approved by the Ethics Committee of the Comissão Nacional Proteção de Dados under the protocol number 3140/2010. All the procedures in this study were in accordance with the 1975 Helsinki Declaration, updated in 2013. Informed consent was obtained from all participants included in the study.

\section{References}

1. Schmitt J, Duray G, Gersh BJ, Hohnloser SH. Atrial fibrillation in acute myocardial infarction: a systematic review of the incidence, clinical features and prognostic implications. Eur Heart J. 2009;30(9):1038-45.

2. Gorenek B, Kudaiberdieva G. Atrial fibrillation in acute ST-elevation myocardial infarction: clinical and prognostic features. Curr Cardiol Rev. $2012 ; 8(4): 281-9$

3. Walkey AJ, Hogarth DK, Lip GYH. Optimizing atrial fibrillation management: from ICU and beyond. Chest. 2015;148(4):859-64.

4. Kuipers S, Klein Klouwenberg PM, Cremer OL. Incidence, risk factors and outcomes of new-onset atrial fibrillation in patients with sepsis: a systematic review. Crit Care. 2014;18(6):688

5. Jabre P, Roger VL, Murad MH, Chamberlain AM, Prokop L, Adnet $F$, et al. Mortality associated with atrial fibrillation in patients with myocardial infarction: a systematic review and meta-analysis. Circulation. 2011;123(15):1587-93.

6. Lopes RD, Pieper KS, Horton JR, Al-Khatib SM, Newby LK, Mehta RH, et al. Short- and long-term outcomes following atrial fibrillation in patients with acute coronary syndromes with or without ST-segment elevation. Heart. 2008;94(7):867-73.

7. Gibson CM, Mehran R, Bode C, Halperin J, Verheugt F, Wildgoose P, et al. An open-label, randomized, controlled, multicenter study exploring two treatment strategies of rivaroxaban and a dose-adjusted oral vitamin Kantagonist treatment strategy in subjects with atrial fibrillation who undergo percutaneous coronary intervention (PIONEER AF-PCI). Am Heart J. 2015;169(4):472-8.

8. Alasady M, Abhayaratna WP, Leong DP, Lim HS, Abed HS, Brooks AG, et al. Coronary artery disease affecting the atrial branches is an independent determinant of atrial fibrillation after myocardial infarction. Heart Rhythm. 2011;8(7):955-60.

9. Goldberg R, Yarzebski J, Lessard D, Wu J, Gore JM. Recent trends in the incidence rates of and death rates from atrial fibrillation complicating initial acute myocardial infarction: acommunity-wide perspective. Am Heart J. 2002;143(3):519-27.

10. Rubenstein J, Cinquegrani MP, Wright J. Atrial fibrillation in acute coronary syndrome. J Atr Fibrillation. 2012;5(1):551.

11. Kinjo K, Sato H, Ohnishi Y, Hishida E, Nakatani D, Mizuno H, etal. Prognostic significance of atrial fibrillation/atrial flutter in patients with acute myocardial infarction treated with percutaneous coronary intervention. Am J Cardiol. 2003;92(10):1150-4

12. Walkey AJ, Wiener RS, Ghobrial JM, Curtis LH, Benjamin EJ. Incident stroke and mortality associated with new-onset atrial fibrillation in patients hospitalized with severe sepsis. JAMA. 2011;306(20):2248-54.
13. Ibanez B, James S, Agewall S, Antunes MJ, Bucciarelli-Ducci C, Bueno H, et al. 2017 ESC Guidelines for the management of acute myocardial infarction in patients presenting with ST-segment elevation: The Task Force for the management of acute myocardial infarction in patients presenting with STsegment elevation of the European Society of Cardiology (ESC). Eur Heart]. 2018;39(2):119-77.

14. Kirchhof P, Benussi S, Kotecha D, Ahlsson A, Atar D, Casadei B, et al. 2016 ESC Guidelines for the management of atrial fibrillation developed in collaboration with EACTS. Eur Heart J. 2016;37(38):2893-2962.

15. Lopes RD, Elliott LE, White HD, Hochman JS, Van de Werf F, Ardissino D, et al. Antithrombotic therapy and outcomes of patients with atrial fibrillation following primary percutaneous coronary intervention: results from the APEX-AMI trial. Eur Heart J. 2009;30(16):2019-28.

16. Dewilde WJ, Oirbans T, Verheugt FW, Kelder JC, De Smet BJ, Herrman JP, et al. Use of clopidogrel with or without aspirin in patients taking oral anticoagulant therapy and undergoing percutaneous coronary intervention: an open-label, randomised, controlled trial. Lancet. 2013;381(9872):1107-15.

17. Gong X, Tang S, Li J, Zhang X, Tian X, Ma S. Antithrombotic therapy strategies for atrial fibrillation patients undergoing percutaneous coronary intervention: a systematic review and network meta-analysis. PLoS One. 2017;12(10):e0186449.

18. Stenestrand U, Lindback J, Wallentin L, RIKS-HIA Registry. Anticoagulation therapy in atrial fibrillation in combination with acute myocardial infarction influences long-term outcome: a prospective cohort study from the Register of Information and Knowledge About Swedish Heart Intensive Care Admissions (RIKS-HIA). Circulation. 2005;112(21):3225-31.

19. McMurray J, Kober L, Robertson M, Dargie H, Colucci W, Lopez-Sendon J, et al. Antiarrhythmic effect of carvedilol after acute myocardial infarction: results of the Carvedilol Post-Infarct Survival Control in Left Ventricular Dysfunction (CAPRICORN) trial. J Am Coll Cardiol. 2005;45(4):525-30.

20. Pederson OD, Bagger H, Kober L, Torp-Pedersen C. Trandolapril reduces the incidence of atrial fibrillation after acute myocardial infarction in patients with left ventricular dysfunction. Circulation. 1999;100(4):376-80.

21. Danchin N, Fauchier L, Marijon E, Barnay C, Furber A, Mabo P, et al. Impact of early statin therapy on development of atrial fibrillation at the acute stage of myocardial infarction: data from the FAST-MI register. Heart. 2010;96(22):1809-14.

22. Batra G, Svennblad B, Held C, Jernberg T, Johanson P, Wallentin L, et al. All types of atrial fibrillation in the setting of myocardial infarction are associated with impaired outcome. Heart. 2016;102(12):926-33. 
23. Sibley S, Muscedere J. New-onset atrial fibrillation in critically ill patients. Can Respir J. 2015;22(3):179-82.

24. Moss TJ, Calland JF, Enfield KB, Gomez-Manjarres DC, Ruminski C, DiMarco JP, et al. New-onset atrial fibrillation in the critically III. Crit Care Med. 2017;45(5):790-7.

25. Bosch NA, Cimini J, Walkey AJ. Atrial fibrillation in the ICU. Chest. 2018;154(6):1424-34.

26. Wong C-K, White HD, Wilcox RG, Criger DA, Califf RM, Topol EJ, et al. Significance of atrial fibrillation during acute myocardial infarction, and its current management: insights from the GUSTO-3 trial. Card Electrophysiol Rev. 2003;7(3):201-7.

27. Kyriakidis M, Barbetseas J, Antonopoulos A, Skouros C, Tentolouris C, Toutouzas P. Early atrial arrhythmias in acute myocardial infarction. Chest. 1992;101(4):944-7.
28. Tjandrawidjaja MC, Fu Y, Kim DH, Burton JR, Lindholm L, Armstrong PW, et al. Compromised atrial coronary anatomy is associated with atrial arrhythmias and atrioventricular block complicating acute myocardial infarction. J Electrocardiol. 2005;38(3):271-8.

29. Yamashita T, Murakawa Y, Ajiki K, Omata M. Incidence of induced atrial fibrillation/flutter in complete atrioventricular block. A concept of 'atrialmalfunctioning' atrio-hisian block. Circulation. 1997;95(3):650-4.

30. Celik T, lyisoy A, Kursaklioglu H, et al. Effects of primary percutaneous coronary intervention on p wave dispersion. Ann Noninvasive Electrocardiol. $2005 ; 10(3): 342-7$

31. Akdemir R, Ozhan $\mathrm{H}$, Gunduz $\mathrm{H}$, et al. Effect of reperfusion on P-wave duration and $\mathrm{P}$-wave dispersion in acute myocardial infarction: primary angioplasty versus thrombolytic therapy. Ann Noninvasive Electrocardiol. 2005;10(1):35-40. 